\title{
POST THYROIDECTOMY COMPLICATIONS- OUR EXPERIENCE IN TERTIARY CARE HOSPITAL
}

\author{
V. Satyanarayana Murthy¹, Waddi Sudhakar², Naveen Kumar Podili3 ${ }^{3}$ Ramya Sai Adusumalli ${ }^{4}$
}

1Associate Professor, Department of Surgery, RIMS, Srikakulam.

${ }^{2}$ Associate Professor, Department of Surgery, ACSR, GMC, Nellore, Andhra Pradesh

3 Postgraduate Student, Department of Surgery, Andhra Medical College.

4 Postgraduate Student, Department of Surgery, Andhra Medical College.

\section{BACKGROUND}

ABSTRACT

Thyroidectomy is a very common surgical procedure worldwide and is performed by surgeons with varied training. The outcome and complication rates are largely dependent on surgeon's skill and experience, the extent of surgery, indication of surgery and number of thyroid surgeries performed at that particular centre. The objective of this study is to determine the frequency of postoperative complications after thyroid surgery in a tertiary care hospital, Vishakhapatnam.

The purpose of this study is to assess the early complications of total thyroidectomy and risk factors which leads to these complications.

\section{MATERIALS AND METHODS}

It was a retrospective descriptive study and was carried out over a period of 3 years from January 2014 to December 2017 . A total of 179 patients of thyroid swelling, who underwent total thyroidectomy are assessed over a period of 3 years. All patients with thyroid swelling who underwent total thyroidectomy irrespective of cause of thyroid swelling were included in this study. Patient's biodata including age, sex, clinical status of thyroid, thyroid function tests, ultrasound, fine needle aspiration cytology and operative procedure, findings, post-operative complications and histopathology were recorded.

\section{RESULTS}

A total of 179 cases of thyroid swelling who underwent total thyroidectomy were assessed. The overall post-operative complication rate was $20.11 \%$ (36 cases). Post-operative hypocalcaemia was the most frequent complication observed in 33 cases. Most of the hypocalcaemia is transient in immediate post-operative period; permanent being observed in 4 cases. Recurrent laryngeal nerve (RLN) injury was noted in $10(5.5 \%)$ patients. The complications like bleeding leading to haematoma formation was observed in one case for which immediate exploration was done; seroma formation in 15 cases. Tracheal and oesophageal injuries were identified in 5 and 2 cases respectively, which were due to extensive infiltration of these structures by malignant thyroid disease. Complications like wound infection, superior laryngeal nerve injury and sympathetic chain injury were not observed in our study. Many patie nts had more than one complication.

\section{CONCLUSION}

The commonest post thyroidectomy complication was hypocalcaemia. Male gender, old age and extensive thyroid surgery for malignant thyroid disease and huge goitre were associated with increased complication rate.

\section{KEYWORDS}

Goitre, Total Thyroidectomy, Hypocalcaemia, Recurrent Laryngeal Nerve Injury.

HOW TO CITE THIS ARTICLE: : Murthy VS, Sudhakar W, Podili NK et al. Post thyroidectomy complications- our experience in tertiary care hospital. J. Evolution Med. Dent. Sci. 2017;6(92):6589-6592, DOI: 10.14260/jemds/2017/1428

\section{BACKGROUND}

Total thyroidectomy has been the mainstay of treatment for nearly all primary malignant lesions and certain benign conditions of the thyroid gland at our medical centre. The extent of thyroid gland removal at operation has been widely debated, because more extensive operative procedures carry with them potentially increased complications. The technique of thyroidectomy has been in evolution for many years. The surgical complications following thyroid surgery is dreadful before Billroth and Kocher's era. Theodorus Billroth

'Financial or Other Competing Interest': None.

Submission 24-10-2017, Peer Review 16-11-2017,

Acceptance 22-11-2017, Published 04-12-2017.

Corresponding Author:

Dr. Waddi Sudhakar,

Associate Professor

Department of Surgery,

ACSR, GMC, Nellore, Andhra Pradesh.

E-mail: sudhakarwaddi@yahoo.co.in

DOI: $10.14260 /$ jemds $/ 2017 / 1428$ performed 48 operations between 1877 and 1881 with only four patients $(8.3 \%)$ dying. Theodor Kocher considered the father of thyroid surgery, performed his first thyroidectomy in 1872. He performed 2000 operations with a mortality rate of only $4.5 \%$. He noticed however the patient developed myxoedema, which he called 'Cachexia strumipriva.' Initially, he used vertical skin incision, later changed to transverse collar incision, which is usually associated with his name. For his monumental work, he was awarded Nobel Prize in 1909. Classic articles by Kocher, Halsted, Lahey, Crile and Riddell have provided surgeons with principles that have significantly reduced operative morbidity and mortality from thyroidectomy.[1-5]

\section{MATERIALS AND METHODS}

During the 3-year period from January 2014 to December 2017, a retrospective descriptive study was conducted on 179 patients who underwent total thyroidectomies for malignant or benign disease of the thyroid at the King George Hospital, 
Vishakhapatnam, Andhra Pradesh, India. KGH is a 1085 bedded tertiary care hospital rendering services to the people of North Coastal Andhra Pradesh and adjacent districts of Orissa and Chhattisgarh. The hospital has 24 hours casualty department, 20-bedded surgical intensive care unit, several open wards with capacity for around 250 surgical patients and equipped with two emergency operating rooms.[6]

The records of 179 patients were available for retrospective review and technique of the operation performed, extent of the disease, pathologic findings of excised tissue, degree of recurrent laryngeal nerve injury, degree of post-operative hypoparathyroidism, other perioperative complications and mortality were assessed.

\section{Inclusion Criteria}

All patients with thyroid swelling who underwent total thyroidectomy irrespective of the underlying cause were included.

\section{Exclusion Criteria}

Patients who have preoperative complications like RLN injury either due to idiopathic or malignant infiltration were excluded.

\section{RESULTS}

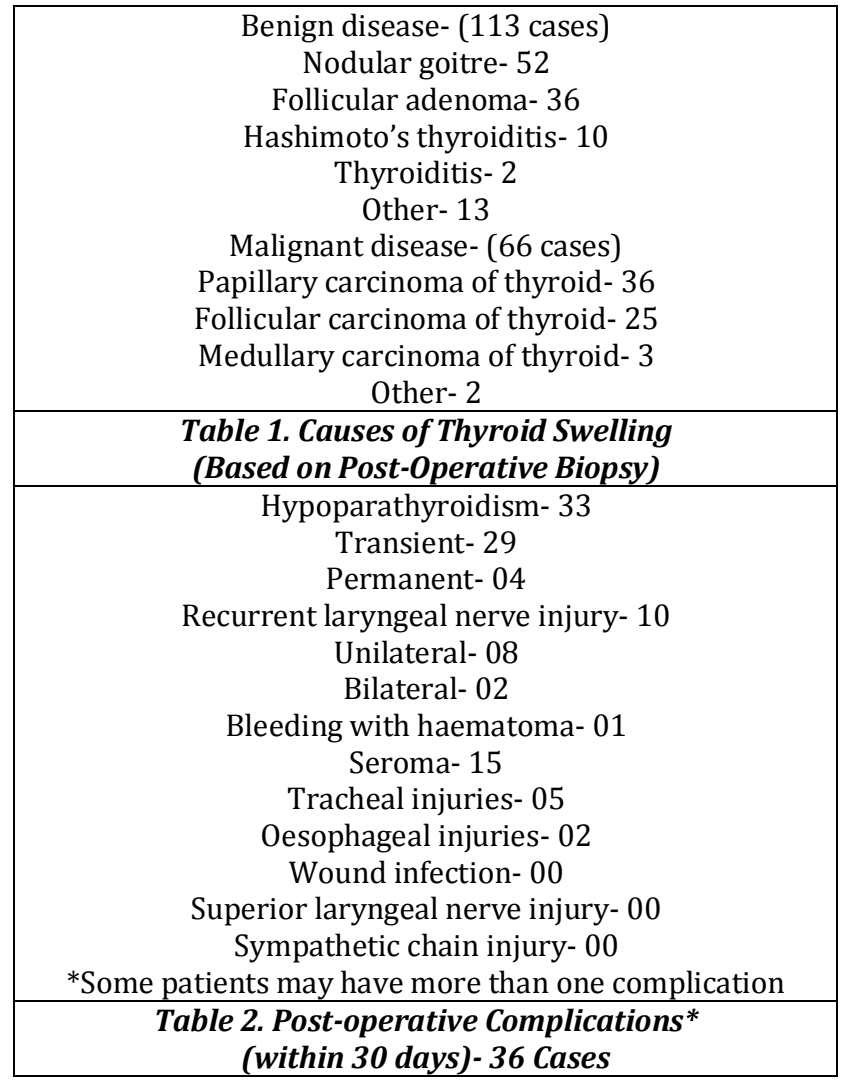

\section{DISCUSSION}

A total thyroidectomy is referred as removal of entire thyroid tissue, while a near-total thyroidectomy leaves less than $1 \mathrm{gm}$ $(1 \mathrm{~cm})$ of thyroid tissue on one side of the neck. It is performed when a total thyroidectomy is planned, but a minute portion of thyroid is purposely left in situ in close proximity to the recurrent laryngeal nerve or parathyroid gland when it is deemed unsafe to do otherwise. One should perform the operation in the most abnormal side of the thyroid first, so that if the nerve is inadvertently injured or invaded by thyroid cancer a less extensive procedure can be performed on the opposite side to ensure that the contralateral nerve is preserved. Bilateral recurrent laryngeal nerve palsy should be avoided at all costs, as this often requires a tracheostomy to protect the patient's airway.[7,8] In a traditional subtotal thyroidectomy, 2 to $3 \mathrm{~g}$ of thyroid tissue is left bilaterally. This is no longer recommended by us and others, because recurrent disease can occur bilaterally and reoperation would place both recurrent laryngeal nerves and all functioning parathyroid glands at risk. Instead a Dunhill subtotal thyroidectomy is now recommended, which involves a total lobectomy and isthmusectomy on the most diseased side and a subtotal resection (leaving approximately $4 \mathrm{~g}$ ) on the contralateral aide. ${ }^{[7,8]}$

A total of 179 patients who underwent total thyroidectomy were retrospectively studied. In our study, we assessed only post-operative complications following total or near total thyroidectomy surgery. Even though most of thyroidectomy was done for benign diseases we considered for total thyroidectomy over subtotal, because recurrent disease can occur bilaterally and reoperation would place both recurrent laryngeal nerves and all functioning parathyroid glands at risk.[8] Among the 179 operated cases, 66 cases were due to malignant aetiology. Among 66 cases, 9 cases were of huge goitre. The FNAC proved to be benign, while post-operative biopsy being malignant (Table 1 ).

The morbidity rate of total thyroidectomy due to postoperative complications being $20.11 \%$ affecting 36 cases, which are comparable with other studies ${ }^{[9,10]}$ [Table 2]. Some cases particularly with huge goitre and malignant disease have experienced more than one complication. In our study, we assessed the patients for 30 days period following surgery for identification of early complications. Post-operative hypocalcaemia was the most frequent complication observed in 33 cases. Most of the hypocalcaemia is transient in immediate post-operative period; permanent being observed in 4 cases. For hypocalcaemia and related symptoms we have taken $7.5 \mathrm{mg} / \mathrm{dL}$ as cut-off, since below this figure the risk of developing hypocalcaemia-related clinical symptoms is high.[10,11,12] But in our study, we focused more on clinical rather than laboratory value. Many are treated with oral calcium with vitamin D. Only few are requiring intravenous calcium. As many patients suffer transient hypocalcaemia, only 4 patients needed lifelong oral calcium supplementation. Patients were considered to be permanently hypoparathyroid if they required treatment longer than 1 year.[8,9,11,12] These permanent hypocalcaemia occurs following surgery for malignant disease with extensive infiltration.

The complication like bleeding leading to haematoma formation was observed in one case, for which immediate exploration was done. This one is observed in goitre case, who underwent surgery for uncontrollable toxicosis despite medical management. This was attributed to high vascularity of thyroid tissue. Various authors also have similar experience of bleeding in immediate post-operatively in toxicosis patients.[13] We observed seroma formation in 15 cases; large goitre with extensive infiltration leading to excessive thyroid dissection and surgery on toxicosis patients being the risk factors.[13,14,15] Tracheal and oesophageal injuries were identified in 2 cases, which were due to extensive infiltration of these structures by malignant thyroid disease. 
Complications like wound infection, superior laryngeal nerve injury and sympathetic chain injury were not observed in our study, which are comparable with other studies.[13]

Recurrent laryngeal nerve (RLN) injury was noted in 10 (5.5\%) patients comparable with other studies.[11,12,16] Among them two cases had bilateral RLN injury, for which we have done elective tracheostomy tube just before endotracheal extubation after surgery. It is a fundamental principle of surgery that a structure must be identified clearly in order not to damage it. However, routine identification of the parathyroid glands and recurrent nerves has not always been accepted. Various authors fail[13] to observe that the intraoperative identification of parathyroid glands affects the rate of hypoparathyroidism. To reduce this incidence of hypoparathyroidism, it has been suggested performing parathyroid autotransplantation at the sternocleidomastoid muscle of any parathyroid excised or without viable vascularisation.[14,16,17] However, we do not have any experience in autotransplantation. There is also no consensus on the utility of routine identification of the recurrent nerve. Although, identification has been associated with a lower rate of complications[18,19,20] and is crucial during extracapsular resection or resection of the posterior nodules. There are authors such as Torre et al who do not consider it necessary, since manipulation can lesion them.[21] Megherbi et al and Kasemsuwan et al did not find a higher or lower rate of recurrent paralysis if identified systematically.[22,23] Both recurrent nerves were routinely identified in our series. Performing capsular dissection of the thyroid is currently recommended, because the recurrent nerve is always extracapsular, the same as vascularisation of the parathyroids, bearing in mind that the nerve passes behind Zuckerkandl's tuberculum lateral to Berry's ligament.[24]

Hyperthyroidism is the main independent risk factor in our study for the development of complications, both transitory and definitive. Similarly, Thomusch et al show in a multivariate study in Germany that hyperthyroidism is a risk factor for the development of surgical complications particularly hypoparathyroidism, but not RLN injury.[14] Although, there are authors who do not find that toxic MGs have a greater risk for RLN injury, ${ }^{[25]}$ most studies show a higher rate of these lesions (4\% to $13 \%$ ).[26,27] We have also experienced similar correlation between toxicosis and hypocalcaemia, but no correlation for recurrent laryngeal nerve. Goitre size is another risk factor. In our study, it is assessed goitre grade or weight of the excised thyroid. These 2 aspects are risk factors for the complications like hypoparathyroidism and dysphonia. McHenry et al[28] showed an increase in post-operative hypoparathyroidism in large $(100 \mathrm{~g})$ and intrathoracic goitres. If we analyse the various known potential risk factors, we see that neither sex nor age act as such in our series. We do not confirm the results of Thomusch et al, who observe that female sex is an additional risk factor for the development of complications like transitory RLN injury and hypoparathyroidism. Simple goitres are reported to have significantly fewer complications than toxic goitres and thyroid carcinomas.[26,27] Our observations were that patients with a simple goitre like not toxic and not malignant had a zero rate of definitive complications. Other risk factors reported include the hospital's volume of operations and the surgeon's experience. However, these are not factors that can be assessed in our series, as all the patients were operated on in the same centre (a hospital with a high rate of endocrine surgery) and by the same professionals.[13]

\section{CONCLUSION}

Despite the fact that total thyroidectomy is a more involved procedure that exposes more parathyroid gland and RLN to surgical risk than unilateral lobectomy, it is an inherently safe procedure, particularly in experienced hands. The post thyroidectomy complications observed in this study were hypocalcaemia, RLN injury, post-operative bleeding, seroma, stitch sinus and wound infection. Extensive thyroid surgery, goitre size and thyrotoxicosis were associated with statistically significant increase in complication rate. While age and sex of the patient is not risk factors for complications.

\section{REFERENCES}

[1] Kocher T. Zur pathologie und therapie des kropfes. Dtsch Z Chirug 1874;4(5-6):417-40.

[2] Halsted WS. The operative story of goiter: the author's operation. Johns Hopkins Rep 1920;19:71-257.

[3] Lahey FH. Routine dissection and demonstration recurrent laryngeal nerve in subtotal thyroidectomy. Surg Gynecol Obstet 1938;66:775-7.

[4] Crile GW. The prevention of abductor paralysis in thyroidectomy. Surg Gynecol Obstet 1929;49:538.

[5] Riddell VH. Injury to recurrent laryngeal nerves during thyroidectomy; a comparison between the results of identification and non-identification in 1022 nerves exposed to risk. Lancet 1956;271(6944):638-41.

[6] Konkena JR, Vayalapalli MR, Podili NK, et al. Spectrum of secondary peritonitis in north coastal Andhra Pradesh, India. J Evid Based Med Healthc 2016;3(65):3536-3541.

[7] Muller PE, Bein B, Robens E, et al. Thyroid surgery according to Enderlen-Hotz or Dunhill: a comparison of two surgical methods for the treatment of Graves' disease. Int Surg 2001;86(2):112-6.

[8] Hay ID, Grant CS, Taylor WF, et al. Ipsilateral lobectomy versus bilateral lobar resection in papillary thyroid carcinoma: a retrospective analysis of surgical outcome using a novel prognostic scoring system. Surgery 1987;102(6):1088-95.

[9] Thompson NW, Harness JK. Complication of total thyroidectomy for carcinoma. Surg Gynecol Obstet 1970;131(5):861-8.

[10] Karlan MS, Catz B, Dunkelman D, et al. A safe technique for thyroidectomy with complete nerve dissection and parathyroid preservation. Head Neck Surg 1984;6(6):1014-9.

[11] Barraclough BH, Reeve TS. Postoperative complications of thyroidectomy: A comparison of 2 series at an interval of 10 years. Aust N Z J Surg 1975;45(1):21-9.

[12] Clark OH. Total thyroidectomy: the treatment of choice for patients with differentiated thyroid cancer. Ann Surg 1986;196(3):361-70.

[13] Thomusch O, Machens A, Sekulla C, et al. Multivariate analysis of risk factors for postoperative complications in benign goiter surgery: prospective multicenter study in Germany. World J Surg 2000;24(11):1335-41. 
[14] Torre G, Borgonovo G, Amato A, et al. Surgical management of substernal goiter: analysis of 237 patients. Am Surg 1995;61(9):826-31.

[15] Thomusch 0, Machens A, Sekulla C, et al. Multivariate analysis of risk factors for postoperative complications in benign goiter surgery: prospective multicenter study in Germany. World J Surg 2000;24(11):1335-41.

[16] Liu Q, Djuricin G, Prinz R. Total thyroidectomy for benign thyroid disease. Surgery 1998;123(1):2-7.

[17] Singh B, Lucente FE, Shaha AR. Substernal goiter: a clinical review. Am J Otolaryngol 1994;15(6):409-16.

[18] Steurer M, Passler C, Denk DM, et al. Advantages of recurrent laryngeal nerve identification in thyroidectomy and parathyroidectomy and the importance of preoperative and postoperative laryngoscopic examination in more than 1000 nerves at risk. Laryngoscope 2002;112(1):124-33.

[19] Hermann M, Alk G, Roka R, et al. Laryngeal recurrent nerve injury in surgery for benign thyroid diseases: effect of nerve dissection and impact of individual surgeon in more than 27,000 nerves at risk. Ann Surg 2002;235(2):261-8.

[20] Wheeler MH. Thyroid surgery and the recurrent laryngeal nerve. Br J Surg 1999;86(3):291-2.
[21] Megherbi MT, Graba A, Abid L, et al. Complications and sequelae of benign thyroid surgery. J Chir Paris 1992;129(1):41-6.

[22] Kasemsuwan L, Nubthuenetr S. Recurrent laryngeal nerve paralysis: a complication of thyroidectomy. J Otolaryngol 1997;26(6):365-7.

[23] Pelizzo MR, Toniato A, Gemo G. Zuckerkandl's tuberculum: an arrow pointing to the recurrent laryngeal nerve. J Am Coll Surg 1998;187(3):333-6.

[24] Fombellida JD, Romea IG, Algara CG, et al. Aspectos quirúrgicos de los bocios multinodulares. A propósito de una serie de 680 casos. Cir Esp 2001;69(1):25-9.

[25] Wagner HE, Seiler CA. Recurrent laryngeal nerve palsy after thyroid gland surgery. Br J Surg 1994;81(2):2268.

[26] Mishra A, Agarwal A, Agarwal G, et al. Total thyroidectomy for benign thyroid disorders in an endemic region. World J Surg 2001;25(3):307-10.

[27] McHenry CR, Piotrowski JJ. Thyroidectomy in patients with marked thyroid enlargament: airway management, morbidity, and outcome. Am Surg 1994;60(8):586-91. 